\title{
PENGUATAN PEMASARAN PRODUK UMKM ASHFA MADU BOROBUDUR MELALUI STRATEGI PRODUCT BRANDING
}

\author{
Ardhin Primadewi*, Tulkhah Mubasyir Anwar, Yustin Yustin, Afan Hafara Sani, \\ Miftakhul Fauzi
}

Program Studi Teknik Informatika, Fakultas Teknik, Universitas Muhammadiyah Magelang, Magelang, Indonesia *Penulis Korespondensi : ardhin@ummgl.ac.id

\begin{abstract}
Abstrak
Usaha Mikro Kecil dan Menengah (UMKM) sejak tahun 1997 hingga saat ini berdiri kokoh di Indonesia. Dalam perkembangan UMKM di Indonesia, perlu inovasi dan strategi dalam pemasaran produk untuk mencapai keberhasilan dan kestabilan UMKM dalam menghadapi Revolusi Industri 4.0. Ashfa Madu Borobudur sebagai UMKM peternak lebah dan penghasil madu yang terletak di Desa Wisata Tanjungsari, Kecamatan Borobudur, Kabupaten Magelang, Provinsi Ja wa Tengah. Ashfa Madu Borobudur belum sepenuhnya menjadi bagian dalam Branding Borobudur y ang ditetapkan Pemenintah Pusat sebagai ka wasan cagar budaya Internasional dan tingkat penjualan produk masih rata-rata. Pengabdian ini bertujuan agar penjualan produk madu meningkat dengan konsumen melakukan repeat order serta menjadi salah satu merek dan tujuan wisata yang dikenal seba gai penghasil madu dan peternak lebah di sekitar kawasan Borobudur. Beberapa potensi yang dimaksimalkan dalam strategi product branding seperti perancangan ulang logo, brosur, kemasan produk dan x-banner serta optimalisasi website Ashfa Madu Borobudur. Dengan implementasi strategi product branding oleh dosen dan mahasiswa KKN PPMT Universitas Muhammadiyah Magelang, kontribusi penjualan online meningkat menjadi sebanyak $28 \%$.
\end{abstract}

Kata kunci: Borobudur; Branding; Digital Marketing; Madu; UMKM.

\begin{abstract}
Micro, Small, and Medium Enterprises (MSMEs) from 1997 untilnow standsfirmly in Indonesia. In the development of MSMEs in Indonesia, it is necessary to innovate and strategy in marketing products to achieve the success and stability of MSMEs in the face of the Industrial Revolution 4.0. Ashfa Madu Borobudur as MSMEs beekeeper and honey producer located in Tanjungsari Tourism Village, Borobudur District. Ashfa Madu Borobudur has not yet fully become part of the Borobudur Branding that has been established by the Central Government as an international cultural heritage area and the level of product sales is still average. This dedication aims to increase the sale of honey products by consumers making repeat orders and becoming one of the brands and tourist destinations around the Borobudur area. Some of the potentials are maximized in product branding strategies such as redesigning logos, brochures, productpackaging, andx-banners as well as optimizing the Ashfa Madu Borobudur website. With the implementation of the product branding strategy bylecturers and students of KKN PPMT University of Muhammadiyah Magelang, the contribution of online sales increased to as much as $28 \%$.
\end{abstract}

Keywords: Borobudur; Branding; Digital Marketing; Honey; Micro Small AndMedium Enterprises.

\section{PENDAHULUAN}

Sejak tahun 1997 di saat krisis ekonomi dunia pada umumnya dan Indonesia pada khususnya melanda, Usaha Mikro Kecil dan Menengah (UMKM) mampu tetap berdiri kokoh di Indonesia (Suci, 2017). UMKM yang dia tur dalam Undang-Undang Republik Indonesia No.20 Tahun 2008 menyatakan bahwa usaha mikro adalah u saha produkt if milik orang perorangan dan/atau ba dan usaha perorangan yang memiliki kriteria usaha mikro (Dhewanto et al., 2018).
UMKM sebagai sektor ekonomi utama yang berperan dalam pertumbuhan perekonomian nasional (Febriyantoro \& Arisandi, 2018). Peran UMKM yaitu pemenuhan kebutuhan masyarakat a kan sebuah produk unggul, membuka lapangan pekerjaan baru dan meningkatkan pendapatan daerah (Irawan \& Affan, 2020).

Data Badan Pusat Stastistik (BPS) merilis keadaan tersebut pasca krisis ekonomi terkait jumlah UMKM yang terus meningkat pertumbuhannya dari 85 juta hingga 107 juta tenaga kerja pada tahun 2012. 
Fenomena ini menjelaskan bahwa UMKM menupakan usaha yang produktif untuk dikembangkan secara makro dan mikro di Indonesia (Febriyantoro \& Arisandi, 2018; Suci, 2017).

Dalam perkembangan UMKM di Indonesia khususnya pa da tantangan Revolusi Industri 4.0 menuntut pemilik dan atau pengelola UMKM untuk bisa bersaing. Menurut Nura'aeni et al (2018) Digitalpreneurship dapat membantu berkembangnya UMKM dengan menggunakan dan memaksimalkan peran intemet sebagai bagian dari media bisnisnya. Khususnya di era teknologi broadband, dimana telah terjadi pergeseran perilaku konsumen, yang tadinya melakukan belanja secara langsung, menjadi beralih kepada perilaku bela nja online (baik melalui e-commerce, media sosial ataupun marketplace) (Hapsoro et al., 2019).

Namun demikian, citra merek yang dihasilkan UMKM terkesan masih belum diakui masyarakat secara luas. Citra merek, simbol/logo dan desain suatu produk dapat dikenal luas dengan adanya branding (Rizaldi \& Putranto, 2018). Branding sebagai strategi dalam persaingan global yang menghasilkan desain, citra merek, dan kesan yang menarik minat konsumen. Mengingat saat ini konsumen tidak hanya mempertim ban gkan rasa tetapi juga estetika dari produk yang a kan dibeli (Irawan \& Affan, 2020). Sedangkan product branding adalah meningkatkan citra merek berbasis pada sebuah produk.

Beberapa UMKM dalam perkembangannya telah mencoba menggunakan product branding untuk meningkatkan popularitas dan kepercayaan masyarakat atas produk yang dihasilkan. Seperti pendampingan produk catering di Kota Malang (Irawan \& Affan, 2020), pengrajin sepatu di Kota Medan (Na sution et al, 2017), produsen PIA Sinar Bali (Diaz et al., 2019), sentra rajutan Binong Jati (Oktaviani \& Rustandi, 2018) dan kerajinan tas di Desa Gulang (Susanti, 2018). Beberapa dari UMKM tersebut didampingi dalam pengabdian khususnya dengan meningkatkan pengetahuan dan skill untuk bisa bersaing pada pasar online. Khususnya pengetahuan dan skill terka it digital marketing sehingga pengelola UMKM dapat melakukan pemasaran produk dan jasa melalui media intemet (Amrullah et al., 2019).

Ashfa Madu Borobudur a dalah UMKM peternak lebah dan penghasil madu sebagai sebuah usaha ekonomi produktif. Produk yang dihasilkan yaitu madu asli, madu lanceng, madu pahit bunga kaliandra, madu asli binga kopi dan madu rambutan. Selain itu juga terdapat produk turunan madu yaitu madu bee pollen, royal jelly dan rotilebah.

Ashfa Madu Borobudur berdiri sendiri dan milik perorangan yang terletak di Desa Wisata Tanjungsari, Keca matan Borobudur, Kabupaten Magelang, Provinsi Jawa Tengah. Ashfa Madu Borobudur berjarak 2,8 km da ri Taman Wisata Candi Borobudur dan 500 meter dari
Balkondes Tanjungsari. Secara umum, Kecamatan Borobudur mempunyai luas wila yah sekitar $54,55 \mathrm{~km}^{2}$.

Dalam perkembangan usahanya, Ashfa Madu Borobudur yang terletak di kaki pegunungan menoreh membangun usaha yang lebih prospektif dengan memaksimalkan potensi peternakan lebah. Ashfa Madu Borobudur memiliki 3 peternakan yang terletak 2 diantaranya di perbukitan menoreh dan 1 di Desa Tanjungsari. Ashfa Madu Borobudur menerima kunjungan darituris domestik dan turis a sing yang ingin mengetahui lebih dekat proses panen madu ataupun kehidupan lebah di peternakan lebah. Kunjungan ini disebut juga dengan wisa ta edukasi.

Kunjungan ke peternakan lebah ini sebagai bentuk kerja sama antara Ashfa Madu Borobudur dengan agen wisata yang mengelola seperti VW Tour Borobudur. Area yang dijelajahi $V W$ Tour Borobudur dengan mengelilingi desa wisata yang berada di sekitar Candi Borobudur menggunakan mobil kuno Volks Wagen. Tujuan wisa ta seperti Balkondes, tempat pembuatan gerabah, tempat membatik, dan peternakan lebash Ashfa Madu Borobudur. Ketertarikan turis dengan peternakan lebah sangat bergantung pada populantas a gen wisa ta tersebut.

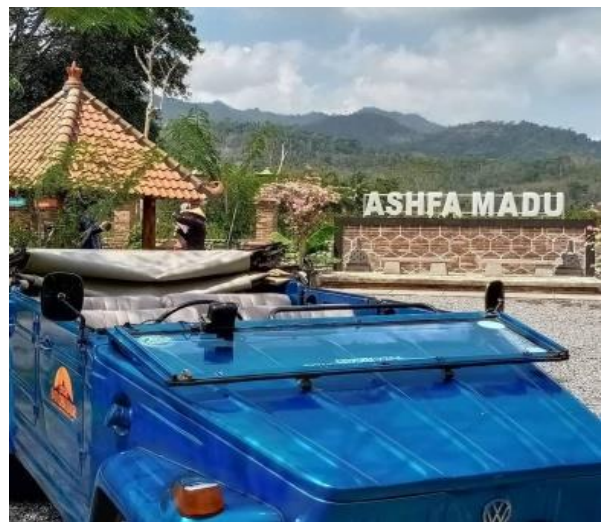

Gambar 1. Kemitraan dengan VWTour Borobudur.

Sebagai bentuk pemasaran produk, Ashfa Madu Borobudur telah mencoba memulai proses digital marketing sebagai salah satu media promosi. Sebelum mahasiswa melaksanakan Kuliah Kerja Nyata Penga bdian Kepada Masyarakat Terpadu (KKNPPMT) dilaksanakan, mahasiswa telah melakukan proses wa wancara dan observasi.

Hasil wa wancara dan observasi ke la pangan diketahui bahwa Ashfa Madu Borobudur telah memiliki website sederhana dengan hosting gratis dan media sosial (Facebook dan Instagram) dengan a kun khusus sesuai nama UMKM. Website yang ada baru terisi 2 halaman menampilkan produk dengan foto sederhana. Website tersebut terakhir diperbaharui 2 tahun yang lalu. Facebook dan Instagram Ashfa Madu Borobudur menampilkan beberapa foto lama dari tamu yang berkunjung pada peternakan lebah. Berdasarkan analisis situasi, dapat teridentifikasi beberapa permasalahan yang dihadapi oleh mitra, yaitu: 
1) Masih rendahnya pemahaman tentang product branding sebagai bagian dari strategi pemasaran produk.

2) Kurangnya pemahaman pemilik dan pengelola Ashfa Madu Borobudur mengenai pentingnya promosi menggunakan digitalmarketing.

3) Perlu adanya pelatihan dan pendampingan untuk meningkatkan kemampuan dan pengetahuan pemilik dan karyawan Ashfa Madu Borobudur khususnya untuk membuat konten yang akan diunggah pada media sosial yang menjadi bagian da ri keberhasilan digital marketing.

4) Kurangnya aktivitas komunikasi dan pemasaran kepa da masyarakat terkait dengan aktivitas bisnis UMKM.

5) Ashfa Madu Borobudur belum sepenuhnya menjadi bagian dalam Branding Kawasan Wisata Borobudur yang ditetapkan Pemerintah Pusat sebagai kawasan cagar budaya Internasional.

6) Khusus pada kunjungan peternakan lebah, Ashfa Madu Borobudur sangat tergantung dengan kerja sama dengan agen wisata. Sedangkan omset penjualan terbesar masih tergantung dari turis yang datang ke Ashfa Madu Borobudur.

Dari perma salahan di atas perlu adanya strategi dalam penguatan pemasaran produk Ashfa Madu Borobudur. Pengabdian ini bertujuan agar penjualan produk madu meningkat dengan konsumen melakukan repeat order serta menjadi salah sa tu merek dan tujuan wisata yang dikenal sebagai penghasil madu dan peternak lebah di sekitar kawasan Borobudur. Pengabdian ini memaksimalkan potensi yang sudah dimiliki Ashfa Madu Borobudur den gan menggunakan strategi product branding.

Beberapa potensi yang dimaksimalkan da lam strategi product branding seperti perancangan ulang logo, brosur, kemasan dan x-banner serta optimalisasi web site Ashfa Madu Borobudur. Hal ini lebih sebagai bagian identitas dan citra sebuah UMKM khusunya sebagai visual branding. Ada beberapa poin penting dalam pembentukan identitas dan citra UMKM yang akan digunakan sebagai dasar perancangan brand yaitu kebutuhan untuk membuat identitas brand a gar diakui, menentukan positioning, mengorganisasikan material promosi, serta membuat pengalaman baru bagi turis agarbisa merasakan keunikan suatu UMKM (Gunawan et al., 2013).

\section{METODE}

Penerapan strategi product branding Ashfa Madu Borobudur di Dusun Brongkol, Desa Tanjungsan Kecamatan Borobudur Kabupaten Magelang. Metode perolehan sumber data dalam penulisan karya tulis dengan menggunakan metode wawancara untuk mendapatkan informasi secara langsung yang dapat menjelaskan dan menjawab permasalahan dalam penulisan yang bersangkutan secara obyektif. Penggunaan data sekunder berupa studi kepustakaan denga n membaca literatur- litera tur yang berkaitan serta menunjang penulisan ini. Literatur yang digunakan a dalah literatur- literatur terkait product branding beserta turunannya seperti digital marketing dan visual branding.

Dengan adanya pengabdian ini, bisnis diharapkan dapat meningkatkan kapasitas usaha dan produksi dengan mendapatkan pelatihan dan pendampingan dari akademisi. Dosen dan mahasiswa yang mewakili akademisi sebagai penyedia tenaga ahli sesuai bidangnya. Dalam memaksimalkan strategi product branding, akademisi mengutamakan pendampingan digital marketing khususnya media sosial, optimalisasi website sebagai tools digital marketing dan merancang ulang visual branding a gar Ashfa Madu Borobudur lebih dikenal masyarakat.

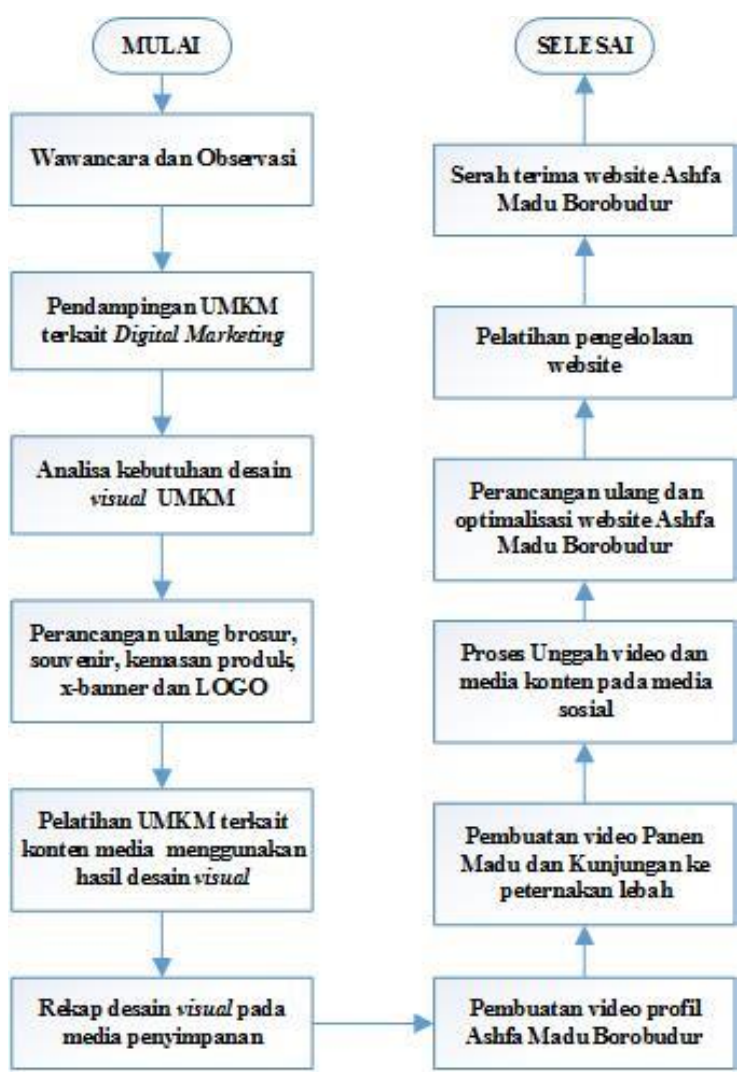

Gambar 2. Skema Kegiatan.

Pada gambar 2 di atas, skema kegiatan yang dilaksanakan selama KKN PPMT dengan memberikan pelatihan dan pendampingan kewira usahaan (seperti teknik digital marketing, perancangan ulang visual branding dan perencanaan pembuatan konten media) serta perancangan ulang website sebagai alat dalam digital marketing.

\section{HASIL DAN PEMBAHASAN}

Kegiata $\mathrm{K}$ KN PPMT berupa strategi product branding ini dilaksanakan untuk menjawab permasalahan dan tantangan jangka panjang yang dihadapi Ashfa Madu Borobudur di Dusun Brongkol, Desa Tanjungsari Kecamatan Borobudur pada khususnya dan Kawasan Wisata Borobudur Kabupaten Magelang pada umumnya. 
Hasil dari KKN PPMT ini berupa kegiatan yang meliputi:

a. Pendampingan UMKMterkait Digital Marketing Kegiatan ini berupa edukasi kepada pengelola Ashfa Madu Borobudur dari Dosen dan Mahasiswa Teknik Informatika Universitas Muhammadiyah Magelang. Pendampingan Digital Marketing(dapat dilihat pada gambar 3) yang total dilaksanakan selama 8 jam dalam 3 kali pertemuan. Pendampingan ini memberi pengetahuan tentang pentingnya melakukan promosi/marketing secara digital, optimalisasi media sosial da n website, serta optimalisasi konten media yang menark konsumen.

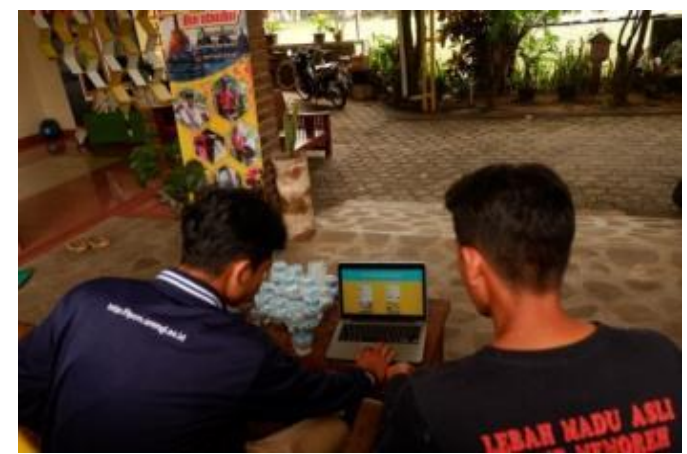

Gambar 3. Pendampingan Digital Marketing.

\section{b. Analisa kebutuhan desain visual UMKM}

Kegiata $n$ ini merupakan la njutan da ri pentingnya digital marketing. Konten media sebagai bagian utama dalam digital marketing perlu divariasikan sehingga menarik konsumen.Berdasarkan hasil diskusi saat pendampingan digital marketing diketahui bahwa perlu perancangan ulang brosur, souvenir, kemasan produk, $\mathrm{x}$-banner dan logo Ashfa Madu Borobudur. Pembuatan desain visual yang menarik dapat membuat konsumen tertarik untuk melihat kemudian membeli serta mengingat a kan produk Ashfa Madu Borobudur. Desain visual a gar tepat guna dengan konten media yang akan diunggah di media sosial perlu dianalisis terlebih dahulu. Kegiatan diawali dengan melakukan observasi konten dilapangan, melakukan wa wa ncara terhadap mitra terkait konten dan terkait ide dan konsep desain yang diinginkan seperti logo, warna, tipografi, advertising, signage, ataupun environtment.

c. Perancangan ulang dan pembuatan desain visual logo, brosur, souvenir, kemasan produk dan $x$ banner

Rancang ulang desain logo untuk meningkatkan brand image di mata konsumen, dimana citra terhadap merek berhubungan dengan preferensi konsumen terhadap suatu merek. Gambar 4 di bawah ini pada bagian sebelah kiri a dalah logoyang lama dan pada bagian sebelah ka nan a dalah logo yang dibuatkan oleh mahasiswa KKN PPMT. Kegiatan selanjutnya adalah mendesain ulang brosur sesuai kebutuhan UMKM dalam menunjukkan potensi produk dan tujuan wisata yang dimilikinya. Desain brosur da pat dilihat pada gambar 5 dibawah ini.
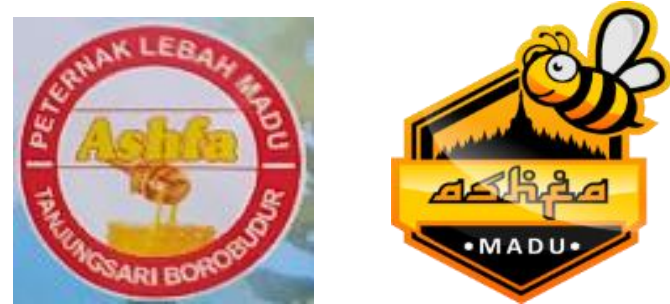

Gambar 4. Logo lama dan logo baru Ashfa Madu Borobudur.

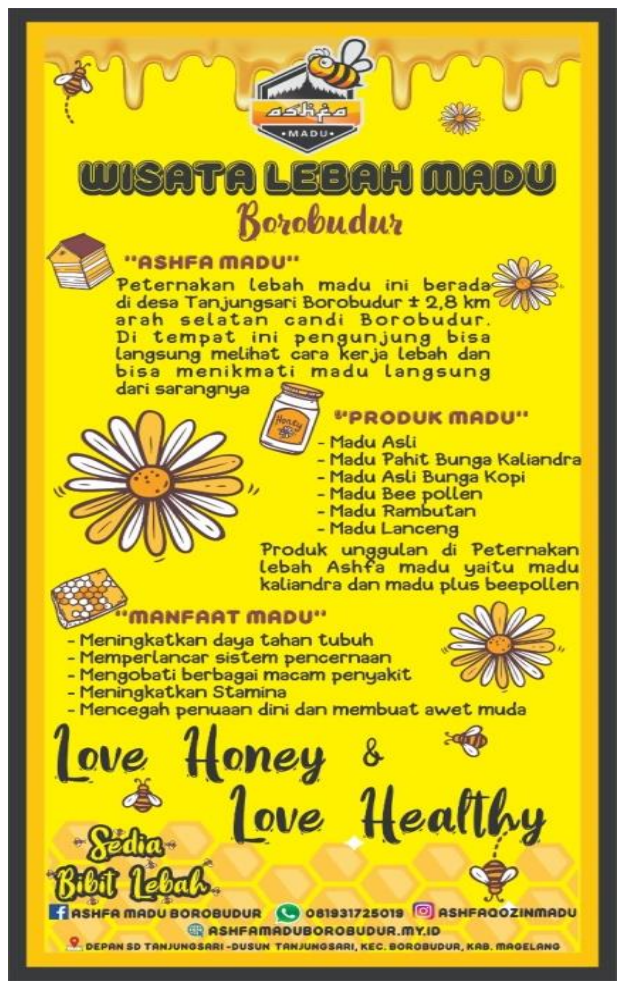

Gambar 5. Desain Brosur.

Selain itu mahasiswa KKN PPMT juga membuat desa in visual souvenir UMKM yang da pat dilihat pada gambar 6 sebelah kiri. Perlu adanya perancangan desain souvenir yang sewaktu-waktu tersedia saat turis berkunjung. Harapannya dengan souvenir tersebut tertera akun media sosial dan a la mat website yang memudahkan a kses dari turis lokal ataupun mancanegara untuk mengakses keseruan kegiatan dan produk madu dari Ashfa Madu Borobudur. Kegiatan selanjutnya adalah desa in kemasan produk yang membawa logo baru dan konsep yang baru. Desain kemasan produk yang dapat dilihat pa da gambar 6 sebelah kanan dibuat untuk memperkenalkan konsep refreshment pada produk Ashfa Madu Borobudur. Pembuatan Xbanner sebagai mini catalogue yang dapat dinikmati oleh pengunjung Ashfa Madu Borobudur. Sehingga turis domestik a taupun a sing dapat dengan mudah mengetahui macam-macam produk turunan madu yang disediakan oleh Ashfa 
Madu Borobudur. Gambar 7 di bawah ini adalah desa in X-banner.
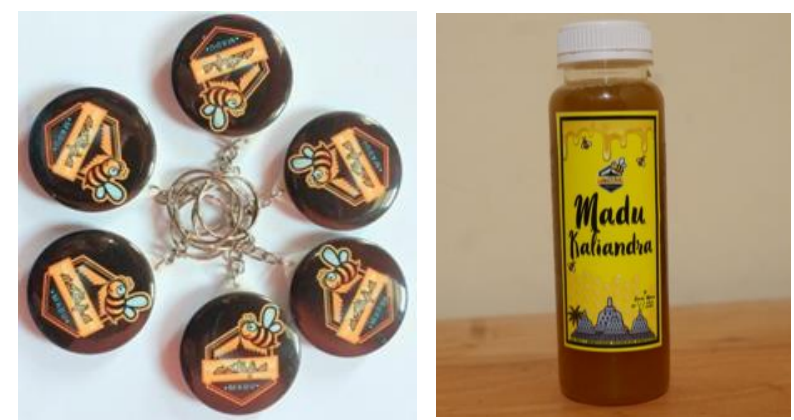

Gambar 6. Desain Souvenir dan desain kemasan Ashfa Madu Borobudur.

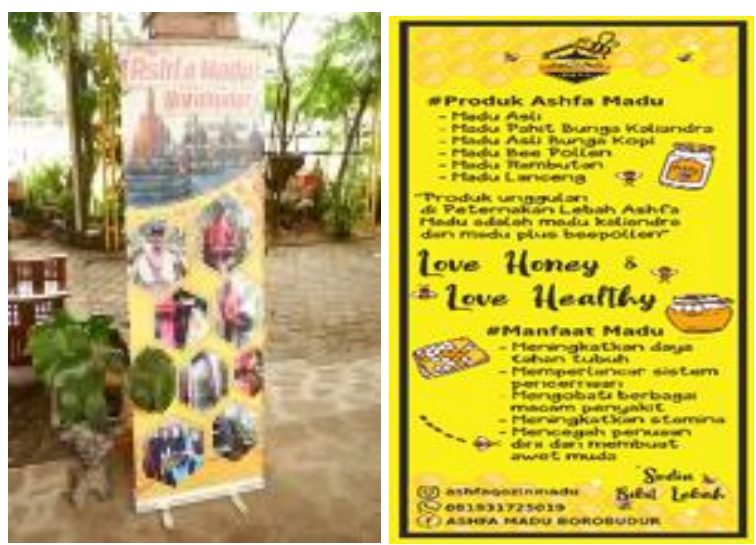

Gambar 7.Desain X-banner la ma (kiri) dan baru (kanan) Ashfa Madu Borobudur.

\section{d. Pelatihan pembuatan konten media} menggunakan hasil desain visual

Konten media yang menarik dapat membuat konsumen tertarik untuk melihat kemudian membeli. Pengelola Ashfa Madu Borobudurdiberi informasi dan data beberapa media sosial yang sudah berhasil meningkatkan penjualan dari media sosial. Pengelola juga didampingi dalam pembuatan konten media baik berupa teks ataupun gambar seperti terlihat pada ga mbar 8 di bawah ini. Dengan adanya kesadaran terkait pentingnya konten media, diharapkan pengelola Ashfa Madu Borobudur semakin semangat dalam mempelajari pembuatan desain visual, video dan optimalisasi website.

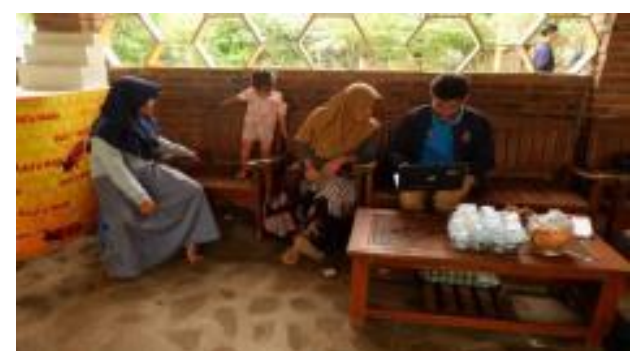

Gambar 8. Pelatihan pembuatankonten media. e. Rekap desain visual logo, brosur, kemasan produk dan $x$-banner

Dari seluruh desain visual diatas kemudian selunuh master desain dari bebera pa alternatif pengerjaan yang dilakukan bersama dengan pengelola Ashfa Madu Borobudur disimpan dalam repositori cloud dan penyimpanan eksternal yang dapat sewaktuwaktu diakses pengelola UMKM.

\section{f. Rangkaian pembuatan video}

Video yang dibuat mahasiswa KKN PPMT adalah video profil Ashfa Madu Borobudur, video panen madu dan video kunjungan ke peternakan lebah. Setiap kegiatan pembuatan video dimulai dengan pembuatan naskah, melakukan rekaman video dan melakukan editing video. Tempat yang dijadikan latar video adalah lokasi Ashfa Madu, perbukitan menoreh dan Desa Tanjungsari.

g. Proses unggah video dan konten media pada media sosial

Setelah proses editing video profil, video panen madu dan kunjungan ke peternakan lebah Ashfa Madu Borobudur, dosen dan mahasiswa melakukan proses uji coba ke pengelola UMKM dan beberapa konsumen. Dari hal tersebut didapatkan feedback yang membangun dalam perbaikan ide editing dalam pembuatan video. Channel Youtube Ashfa Madu Borobudur dapat dilihat pada gambar 9 di bawah ini. Konten media teks dan gambar juga diunggah pada media sosial seperti instagram dan facebook. Optimasi konten media pa da facebook dan instagram (gambar 10 di samping) dengan pendampingan dari dosen dan mahasiswa KKN PPMT. Halini bertujuan tidak hanya meningkatkan webomatric website Ashfa Madu Borobudurnamun juga untuk meningkatkan popularitas Kawasan Borobudur sebagai destinasi wisata.

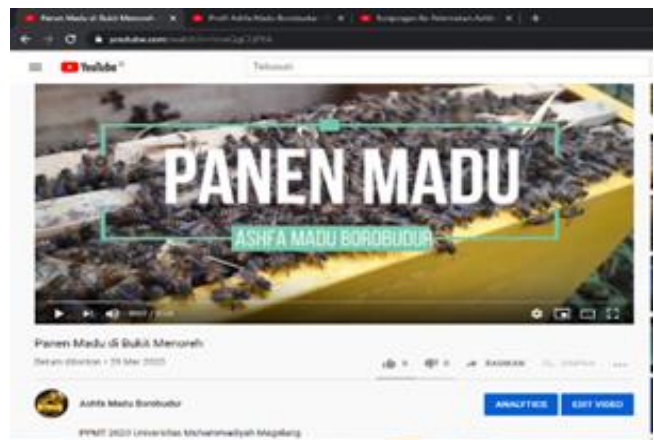

Gambar 9. Publika si Video Di Kanal Youtube. 


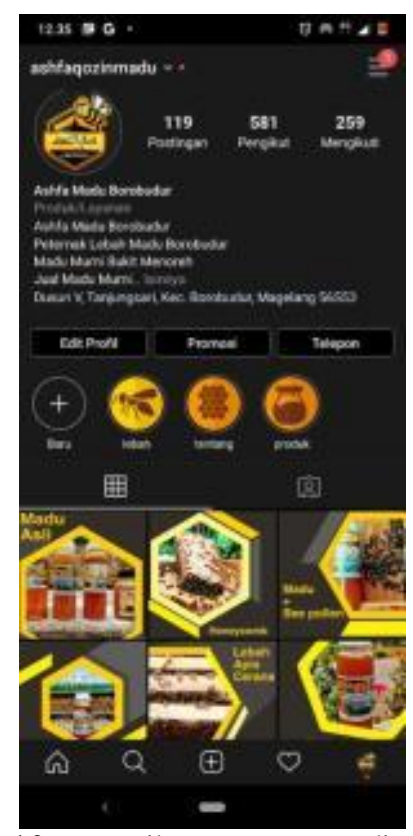

Gambar 10. Tampilan Konten Media Sosial Instagram.

\section{h. Optimalisasi website Ashfa Madu Borobudur}

Perancangan ulang website AshfaMadu Borobudur dilakukan agar sesuai dengan citra brand yang sudah diimplementasikan pada desain visual. Konsep refreshmnet yang menitik beratkan pada sentuhan baru terkait Ashfa Madu Borobudur tercermin pada desain baru website. Gambar 11 di samping merupakan tampilan website lama. Sedangkan gambar 12 adalah tampilan websitebanu yang sudah diubah sedemikian rupa sesuai konsep refreshment. Selain itu tampilan website baru lebih user friendly sehingga mudah digunakan oleh pengelola Ashfa Madu Borobudur dan konsumen. Perubahan konsep dalam product branding dari waktu ke waktu memberikan konsep refreshment pada turis /konsumen yang pernah membeli madu dari Ashfa Madu Borobudur. Website Ashfa Madu Borobudur yang baru terhubung dengan media sosial yang sudah dimiliki Ashfa madu baik facebook, instagram dan youtube.

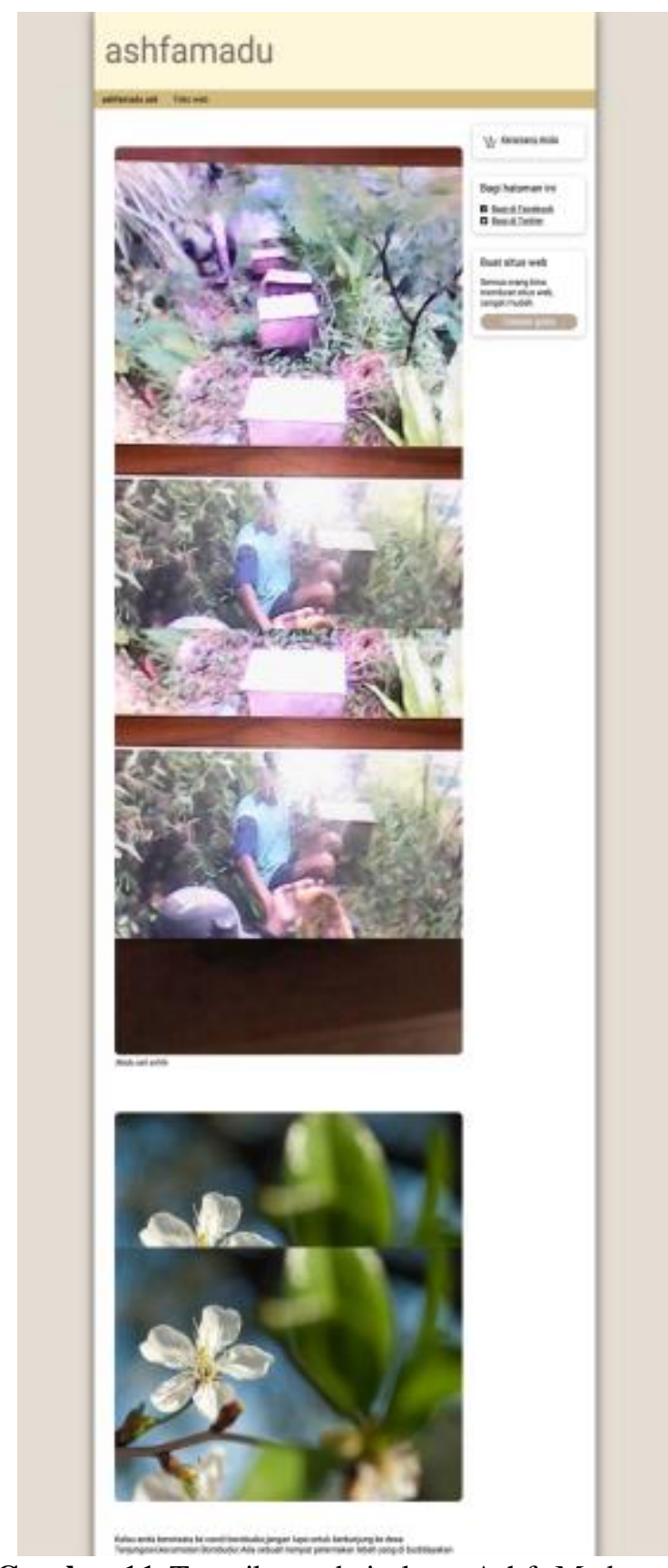

Gambar 11 Tampilan website lama Ashfa Madu Borobudur.

\section{i. Pendampingan pengelolaan website.}

Pengelola diberikan buku panduan pengelolaan website yang sederhana namun tepat guna sesuai kebutuhan. Beberapa hal penting yang disediakan dalam buku adalah proses penyisipan gambar/video/link, proses unggah artikel ban, proses penambahan produk baru dan merubah template website. 


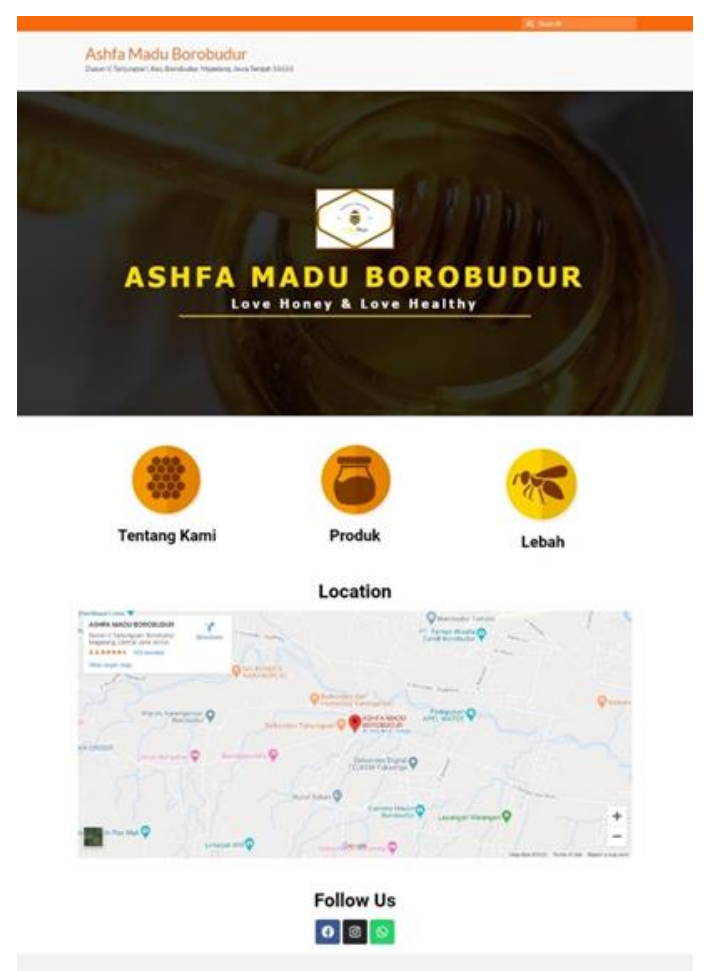

Gambar 12. Tampilan website baru Ashfa Madu Borobudur.

j. Serah terima website dan hasil analisis dampak penggunaan website dalampenjualan

Pada tahun 2019 rata-rata kontribusi penjualan online pada Ashfa Madu Borobudur pada angka 23 $\%$. Pada tabel 1 di bawah ini dapat dilihat bahwa trend penjualan online sejak bulan Februari 2020. Dengan demikian dampak penggunaan website yang sudah diperbaharui pa da angka $28 \%$.

Tabel 1. Data penjualan produk pada awal implementasi website baru tahun 2020.

\begin{tabular}{|c|c|c|c|c|}
\hline Bulan & A & B & $\mathrm{C}$ & D \\
\hline $\operatorname{Jan} 20$ & 145 & 34 & 111 & $23 \%$ \\
\hline Feb 20 & 143 & 41 & 102 & $29 \%$ \\
\hline $\begin{array}{l}\text { Mar } 20 \\
\text { rata-rata }\end{array}$ & $\begin{array}{l}96 \\
\text { contrib }\end{array}$ & $\begin{array}{l}32 \\
\text { sisi }\end{array}$ & 64 & $\begin{array}{l}33 \% \\
28 \%\end{array}$ \\
\hline
\end{tabular}

Keterangan :

$\mathrm{A}=$ Total penjualan, $\mathrm{B}=$ penjualan online, $\mathrm{C}=$ penjualan offline, $\mathrm{D}=$ Kontribusi

\section{KESIMPULAN}

Kesimpulan yang dihasilkan darikegiatan KKNPPMT yang su dah dilaksanakan a dalah sebagai berikut:

1) Hasil evaluasi yang dilakukan kepada pihak mitra di akhir kegiatan menunjukkan bahwa mitra menyatakan materi-materi yang diberikan menunjang kegiatan administrasi yang dikelola. Ma teri digitalmarketing, pengelolaan website, dan media sosial yang diberikan menyatakan runtut dan sistematis.

2) Desain visual Logo, $x$-banner, brosur, kemasan produk dan souvenir yang telah diperbarui oleh mahasiswa KKN PPMT cukup memuaskan pengelola Ashfa Madu Borobudur. Desa in baru ini memberikonsep refreshment dari desain lama yang sudah 6 tahun yang lalu.

3) Video-video y ang di upload di akun youtube Ashfa Madu maupun konten media instagram Ashfa Madu dinyatakan cukup membantu dalam mengenalkan produk kepada masyarakat maupun konsumen madu yang mencari madu melalui jaringaninternet.

4) Antusiasme pihak mitra Ashfa Madu dalam menerima kegiatan KKN PPMT ini sangat baik, Hal ini berdampak pada Ashfa Madu Borobudur lebih dikenal di ma syarakat secara luas.

5) Pihak Ashfa Madu Borobudur juga merasa bahwa kegia tan KKN PPMT ini memberikan pengetahuan baru tentang pentingnya digital marketing dalam melakukan promosi maupun proses jual beli madu.

6) Pihak Ashfa Madu Borobudur menyatakan bahwa masih memerlukan kegiatan pelatihan dan pendampingan sejenis di ma sa yang akan datang.

\section{UCAPAN TERIMA KASIH}

Ucapan terima kasih terutama ditujukan kepada Ashfa Madu Borobudur dan pemerintah Desa Tanjungsari yang berkenan sebagai pelaksanaan KKN PPMT Universitas Muhammadiyah Magelang. Ucapan terima kasih da pat juga disampaikan kepada pihak-pihak yang membantu pelaksanaan pengabdian.

\section{DAFTAR PUSTAKA}

Amrullah, Y. A., Yogyakarta, D. I., \& Resto, S. (2019). Penguatan Digital Marketing. Seminar Hasil Pengabdian Masyarakat, November.

Dhewa nto, W., Lantu, D. C., Herliana, S., \& Azzahra, S. (2018). The entrance mode for small and medium enterprises in the Indonesian fashion industry to international market. International Journal of Business Innovation and Research, 16(3), $267-284$. https://doi.org/10.1504/IJBIR.2018.092619

Diaz, R. A. N., Harsemadi, I. G., Arini, N. W. S., Sulistyorini, E., \& Wedasari, N.L. N. M. (2019). OPTIMALISASI PEMASARAN MELALUI BRAND PACKAGING DAN E-COMMERCE SEBAGAI MEDIA PROMOSI PIA SINAR BALI. Prociding SENADIMAS, 331-336.

Febriyantoro, M. T., \& Arisandi, D. (2018). Pemanfaatan Digital Marketing Bagi Usaha Mikro, Kecil Dan Menengah Pada Era MasyarakatEkonomi Asean. Jurnal Manajemen Dewantara, $\quad 1(2), \quad 61-76$. http://ejournal.stiedewantara.ac.id/index.php/JM $\mathrm{D} /$ issue/view/32

Gunawan, R., PK, A., \& Margana. (2013). PERANCANGAN DESTINATION BRANDING DESA PONCOKUSUMO , MALANG. Jurnal DKVAdiwarna, 1(2), 1-10.

Hapsoro, B. B., Palupiningdyah, \& Sla met, A. (2019). Peran Digital Marketing sebagai Upaya Peningkatan Omset. Jurnal Pengabdian Masyarakat, 23(2), 117-120. https://doi.org/http://dx.doi.org/10.15294/abdim 
a s.v23i2.17880

Irawan, D., \& Affan, M. W. (2020). Pendampingan Branding Dan Packaging Umkm Ikatan Pengusaha Aisyiyah Di Kota Malang. Jurnal Pengabdian Dan Peningkatan Mutu Masyarakat (Janayu), $\quad$ 1(1), 32-36. https://doi.org/10.22219/janayu.v1i1.11188

Nasution, M. I., Pra yogi, M. A., \& Nasution, S. M. A. (2017). Pembinaan Pengelolaan Manajemen Usaha Dan E-Marketing Pada Pelaku Usaha Industri Mikro Pengrajin Sepatu Di Kecamatan Medan Denai. Jurnal Pengabdian Kepada Masyarakat, 23(2), 292. https://doi.org/10.24114/jpkm.v23i2.7028

Nura'aeni, E., Lidinillah, D., \& Pranata, O. (2018). Pengembangan digitalpreneurship mela lui model quadruple helix untuk mahasiswa BIDIKMISI di UPI kampus Tasikmalaya. Seminar Hasil Pengabdian Kepada Masyarakat, 6(2), 117-124.

Okta viani, F., \& Rustandi, D. (2018). Implementasi Digital Marketing dalam Membangun Brand Awa reness. PRofesi Humas : Jurnal Ilmiah Ilmu Hubungan Masyarakat, 3(1), 1. https://doi.org/10.24198/prh.v3i1.15878

Rizaldi, T., \& Putra nto, H. A. (2018). Penerapan Digital Marketing sebagai Strategi Marketing dan Branding pada UMKM. Prosiding, 56-59. https://publikasi.polije.ac.id/index.php/prosidin g/article/view/1186

Suci, Y. R. (2017). Development of MSME (Micro, Small and Medium Enterprises) in Indonesia. Jurnal Ilmiah Cano Ekonomos, 6(1), 51-58.

Susanti, N. (2018). Perancangan E-Marketing Umkm Kerajinan Tas. Simetris: Jurnal Teknik Mesin, Elektro Dan Ilmu Komputer, 9(1), 717-722. https://doi.org/10.24176/simet.v9i1.2042 